\title{
Without compromising surgical outcomes, neoadjuvant therapy might be a better approach to improve the prognosis of patients with advanced pancreatic cancer
}

\author{
Shao-Cheng Lyu, Jing Wang, Ren Lang \\ Department of Hepatobiliary and Pancreaticosplenic Surgery, Beijing Chao Yang Hospital, Capital Medical University, Beijing, China \\ Correspondence to: Ren Lang, Professor. No. 8 Gongtinan Road, Chaoyang District, Beijing 100020, China. Email: dr_langren@126.com. \\ Response to: Wang L, Zhang X, Lu Y, et al. Letter to the editor: the nonnegligible effect of neoadjuvant therapy for patients with borderline resectable \\ pancreatic ductal adenocarcinoma. Gland Surg 2021. doi: 10.21037/gs-21-379
}

Submitted Jun 21, 2021. Accepted for publication Jul 07, 2021.

doi: $10.21037 / g s-2021-06$

View this article at: https://dx.doi.org/10.21037/gs-2021-06

We would like to take this opportunity to respond to some of the questions raised by Dr. Li Wang in the subsequent comments of our paper "prognostic analysis of pancreatic carcinoma with portal system invasion following curative resection" (1). First of all, we strongly agree with Dr. Li's view of neoadjuvant therapy for borderline resectable pancreatic cancer. In 2006, Varadhachary et al. (2) of Anderson Cancer Center in the United States put forward criteria of borderline resectable pancreatic cancer for the first time, and defined the patients with vascular invasion of pancreatic cancer suitable for surgical treatment. Then, in 2009, the American Hepatobiliary and Pancreatic Association issued a consensus among experts on borderline resectable pancreatic cancer (3). Since then, extended radical pancreatectomy combined with vascular resection and reconstruction has played a leading role in the treatment of borderline resectable pancreatic cancer. Meanwhile, with the application of neoadjuvant therapy in pancreatic cancer, especially the proposal of FOLFIRINOX regimen, more and more retrospective studies have shown that neoadjuvant therapy can improve the $\mathrm{R} 0$ resection rate of surgery $(4,5)$, thus improving the long-term prognosis of patients. Since 2014, NCCN guidelines have recommended neoadjuvant therapy for patients with high risk factors (high CA19-9 level, large primary tumor, enlarged lymph nodes, significant weight loss and severe pain) in addition to direct surgery for borderline resectable patients.

In 2016, Professor Matthew (6) published the results of the III phase A021101 study of FOLFIRINOX regimen for borderline resectable pancreatic cancer, laying the foundation for neoadjuvant therapy as a first-line treatment for borderline resectable pancreatic cancer. Therefore, since 2016, the NCCN guidelines recommend that all patients with borderline resectable pancreatic cancer receive priority neoadjuvant therapy. However, the controversy about neoadjuvant therapy and direct surgery has not stopped, and the focus of the dispute mainly lies in the conversion rate of neoadjuvant therapy, standardized course of treatment and the best timing of operation (7). At present, most of the literatures of high quality evidence are from European and American countries, and the comparison of prognosis is usually limited to the comparison between the successful conversion of neoadjuvant therapy and the patients undergoing direct surgery (8), without the overall comparison between the two treatment groups. Therefore, the real world outcome after neoadjuvant therapy in Chinese people remains to be unclear.

In our published paper, our review period is from 2011 to 2018. Due to the change of treatment concept and the screening of patients in the department, only 3 patients received neoadjuvant therapy before operation were enrolled. Therefore, it can not be listed separately for statistical analysis. Meanwhile, because neoadjuvant therapy in our hospital is not carried out in our department, patients' compliance and other problems, it is impossible to estimate the actual surgical conversion rate for Chinese people. In the past two years, with the deepening of the concept of neoadjuvant therapy, we have performed surgery on some patients after neoadjuvant therapy. According to our few preliminary experiences, the survival period of patients after 
neoadjuvant therapy can be extended. The patient who received the earliest neoadjuvant therapy has survived for 38 months after surgery, but whether it is better than patients undergoing direct surgery on the whole still needs further data accumulation. As for the real-world surgical conversion rate of neoadjuvant therapy, we need to further expand cooperation with relevant departments to study.

In addition, it is really interesting whether neoadjuvant therapy can reduce the incidence of pancreatic fistula mentioned by the author. From our intraoperative experience, after neoadjuvant therapy, the texture of the pancreas was hard and the adhesion with the surrounding tissue was so dense that we suspected whether the tumor had progressed locally during the operation. But our intraoperative freezing and postoperative pathology showed that it was only a simple inflammatory reaction. We believe that this change is related to the local inflammatory response after tumor necrosis, this dense adhesion actually increases the difficulty of perivascular nerve plexus and lymph node dissection during the operation, and the right timing of operation may better avoid this problem. As to whether it will reduce the incidence of pancreatic fistula, our data are not yet able to draw this conclusion, but from the current internationally recognized risk assessment of pancreatic fistula (9), neoadjuvant therapy should have potential advantages in this respect. However, due to the large number of variables affecting pancreatic fistula, a large sample analysis is needed to draw the final conclusion.

From our limited experience at present, we agree with the significance of neoadjuvant therapy in borderline resectable pancreatic cancer, and we hope that future research can go deep into how to screen patients with effective neoadjuvant therapy before operation. Only in this way can we achieve real individualized treatment for patients and ultimately improve the overall prognosis of patients with pancreatic carcinoma.

\section{Acknowledgments}

Funding: This study was supported by Beijing Municipal Science \& Technology Commission, China (Grant No. Z181100001718164) Capital's Funds for Health Improvement and Research, Beijing, China (CFH 2020 -2-2036).

\section{Footnote}

Provenance and Peer Review: This article was a standard submission to the journal. The article did not undergo external peer review.

Conflicts of Interest: All authors have completed the ICMJE uniform disclosure form (available at https://dx.doi. org/10.21037/gs-2021-06). The authors have no conflicts of interest to declare.

Ethical Statement: The authors are accountable for all aspects of the work in ensuring that questions related to the accuracy or integrity of any part of the work are appropriately investigated and resolved.

Open Access Statement: This is an Open Access article distributed in accordance with the Creative Commons Attribution-NonCommercial-NoDerivs 4.0 International License (CC BY-NC-ND 4.0), which permits the noncommercial replication and distribution of the article with the strict proviso that no changes or edits are made and the original work is properly cited (including links to both the formal publication through the relevant DOI and the license). See: https://creativecommons.org/licenses/by-nc-nd/4.0/.

\section{References}

1. Wang J, Lyu SC, Zhou L, et al. Prognostic analysis of pancreatic carcinoma with portal system invasion following curative resection. Gland Surg 2021;10:35-49.

2. Varadhachary GR, Tamm EP, Abbruzzese JL, et al. Borderline resectable pancreatic cancer: definitions, management, and role of preoperative therapy. Ann Surg Oncol 2006;13:1035-46.

3. Evans DB, Farnell MB, Lillemoe KD, et al. Surgical treatment of resectable and borderline resectable pancreas cancer: expert consensus statement. Ann Surg Oncol 2009;16:1736-44.

4. Barnes CA, Chavez MI, Tsai S, et al. Survival of patients with borderline resectable pancreatic cancer who received neoadjuvant therapy and surgery. Surgery 2019;166:277-85.

5. Versteijne E, Vogel JA, Besselink MG, et al. Metaanalysis comparing upfront surgery with neoadjuvant treatment in patients with resectable or borderline resectable pancreatic cancer. Br J Surg 2018;105:946-58.

6. Katz MH, Shi Q, Ahmad SA, et al. Preoperative Modified FOLFIRINOX Treatment Followed by Capecitabine-Based Chemoradiation for Borderline Resectable Pancreatic Cancer: Alliance for Clinical 
Trials in Oncology Trial A021101. JAMA Surg 2016;151:e161137.

7. Truty MJ, Kendrick ML, Nagorney DM, et al. Factors Predicting Response, Perioperative Outcomes, and Survival Following Total Neoadjuvant Therapy for Borderline/Locally Advanced Pancreatic Cancer. Ann Surg 2021;273:341-9.

8. Müller PC, Frey MC, Ruzza CM, et al. Neoadjuvant

Cite this article as: Lyu SC, Wang J, Lang R. Without compromising surgical outcomes, neoadjuvant therapy might be a better approach to improve the prognosis of patients with advanced pancreatic cancer. Gland Surg 2021;10(7):2343-2345. doi: 10.21037/gs-2021-06
Chemotherapy in Pancreatic Cancer: An Appraisal of the Current High-Level Evidence. Pharmacology 2021;106:143-53.

9. Mungroop TH, van Rijssen LB, van Klaveren D, et al. Alternative Fistula Risk Score for Pancreatoduodenectomy (a-FRS): Design and International External Validation. Ann Surg 2019;269:937-43. 